\title{
Asthma in the elderly: the effect of choline supplementation
}

\author{
Michele Columbo* and Albert S. Rohr
}

\begin{abstract}
Background: Asthma in the elderly is poorly understood as very few studies have included these patients. DNA methylation can affect the expression of asthma susceptibility genes. Methyl groups can be produced through a choline dependent pathway. Asthmatics have decreased serum choline. We studied the effect of choline supplementation in elderly asthmatics and associations between different parameters at baseline.
\end{abstract}

Methods: This is a double-blind, placebo-controlled, cross-over study. Thirty asthmatics 65 years old and older were evaluated at baseline and 3, 6, 9, and 12 weeks later. They randomly received choline bitartrate $310 \mathrm{mg}$ and placebo capsules twice daily for 6 weeks.

Results: Ninety percent of the study subjects were atopic and $97 \%$ of them were using inhaled corticosteroids. Choline supplementation did not affect ACT (asthma control test), spirometric values, eosinophil counts or total serum IgE vs. placebo ( $p>0.86$ for all comparisons). In subjects with lower ACT ( $\leq 20)$, lower FEV1 \% (<60\%), or higher eosinophil counts $(\geq 0.6)$, there was similarly no difference between choline and placebo $(p>0.63)$. We found no significant association between eosinophil counts and IgE and the other parameters at baseline including in subjects with lower ACT or on higher inhaled steroid doses $(p>0.09)$. Asthmatic women had lower baseline ACT scores compared to men $(p=0.02)$.

Conclusions: In this study of elderly asthmatics, choline supplementation for 6 weeks did not affect ACT scores, spirometric values, peripheral blood eosinophils, or total serum IgE. These results will require confirmation in larger and longer studies.

Trial registration ClinicalTrials.gov NCT02371993

Keywords: Asthma, Choline, Elderly

\section{Findings}

\section{Background}

The U.S. population older than 65 years of age is growing rapidly and will likely increase to about $25 \%$ of the total population by the year 2050 [1]. Among individuals 65 years old and older, about $7 \%$ have asthma [1]. However, there is little information about asthma in these patients as most asthma studies have ignored this group. Older asthmatics have higher morbidity and mortality and are more likely to be underdiagnosed, undertreated,

*Correspondence: michelecolumbo@msn.com

Division of Allergy and Immunology, Bryn Mawr Hospital, Bryn Mawr, PA, USA and hospitalized compared to their younger counterparts [1].

In elderly patients with asthma, we have previously studied the role of exhaled nitric oxide measurements and vitamin D [2, 3]. Indeed, there is growing interest in the possible role of dietary supplements (e.g., vitamins and methyl donors) in asthma $[4,5]$. However, most of the studies of supplements in asthma have yielded conflicting or negative results $[4,5]$. DNA methylation is a mechanism regulating gene-environment interactions in asthma, and its changes can affect asthma by increasing or decreasing the expression of asthma susceptibility genes $[4,5]$. In humans, dietary methyl groups can be produced through folate and choline dependent pathways. \\ ( BioMed Central}

(c) 2016 Columbo and Rohr. This article is distributed under the terms of the Creative Commons Attribution 4.0 International License (http://creativecommons.org/licenses/by/4.0/), which permits unrestricted use, distribution, and reproduction in any medium, provided you give appropriate credit to the original author(s) and the source, provide a link to the Creative Commons license, and indicate if changes were made. The Creative Commons Public Domain Dedication waiver (http://creativecommons. org/publicdomain/zero/1.0/) applies to the data made available in this article, unless otherwise stated. 
Choline is a water soluble essential nutrient important in neurotransmission, lipid signalling and membrane structure besides being a methyl donor [6]. It forms methionine through the methylation of homocysteine. Choline is contained in foods such as meat, liver, eggs, poultry, fish, shellfish and peanuts. Its deficiency has been associated with neurological and cardiovascular diseases [7]. Mostly without strong scientific evidence, choline supplementation is used for liver disease, neurological diseases including depression, bodybuilding, in pregnant women to prevent neural tube defects and as a supplement in infant formula.

In mice, choline has been shown to decrease airway allergic inflammation and reduce bronchoalveolar lavage eosinophils [8]. Individuals with asthma were found to have decreased serum choline [9]. An open label study of Indian asthmatic adults showed a decrease of bronchial hyperreactivity and use of asthma drugs after choline supplementation [10]. In the same study, there was a reduction of cytokine levels (IL-4 and TNF $\alpha$ ) and cysteinyl leukotrienes in the supernatants of the patients' blood mononuclear cells stimulated with phytohemoagglutinin [10]. In a recent, comprehensive review of vitamins and methyl donors in asthma, it was suggested that the current evidence strongly justifies clinical trials of choline supplementation as an adjuvant treatment in asthma [4].

The main purpose of this study was to investigate the effect of choline supplementation on asthma symptoms, assessed by the asthma control test (ACT), and spirometric values in elderly asthmatics. This is a double-blind, placebo controlled, cross-over study. Secondary objectives of our study included studying whether choline supplementation in elderly asthmatics affects peripheral blood eosinophil counts and total serum IgE levels. We also looked for associations between different parameters at baseline.

\section{Methods}

This study included five study visits (baseline, and 3, 6, 9, and 12 weeks later). Each study subject took one capsule of choline bitartrate (310 mg) (Vitamin Shoppe, North Bergen, NJ) twice daily (total daily dose $=620 \mathrm{mg}$ daily) or one placebo capsule twice daily each for 6 weeks in a double-blind, cross-over design. Individuals with history of gastrointestinal cancers were excluded from this study. The bottles containing the unused capsules were collected at the end of the two study periods, the remaining capsules counted and their number recorded. Compliance with the study based on capsule count was very $\operatorname{good}(>90 \%)$.

Thirty subjects 65 years old and older with asthma were included in the study. Twenty-nine were Caucasian and one was African-American. Current smokers or individuals with a 10 pack/year or longer history of smoking were excluded. Almost all of the study subjects were lifetime nonsmokers. The study subjects were recruited among interested and eligible patients with asthma followed in our practice. Allergic sensitization was verified by allergy skin tests for relevant perennial and seasonal allergens.

Spirometric values were obtained according to the ATS/ARS guidelines by a KoKo Spirometer (nSpire Health, Inc, Longmont, Colorado, USA). The ACT is a tool that allows patients to report asthmatic symptoms on a scale from 1 (severe) to 5 (no symptoms) by answering five questions about asthma control. Values lower than 20 are considered as indicative of suboptimal asthma control. Inhaled steroid doses are expressed as fluticasone equivalent. The inhaled steroids used by the study subjects were fluticasone (17), budesonide (7), mometasone (4), and beclomethasone (1). Long-acting bronchodilators were salmeterol (12) and formoterol (8). The only leukotriene antagonist used by the study subjects was montelukast. Drug treatment remained essentially unchanged throughout the study period. One subject was on prednisone $5 \mathrm{mg}$ daily throughout the study. Peripheral blood eosinophils were enumerated and total serum IgE measured at the Main Line Health Laboratories. This study was approved by the Main Line Hospitals Institutional Review Board (F/N-R15-3427B).

The primary endpoint of this study was to evaluate the effect of choline supplementation on the ACT scores. The goal was set to see a $10 \%$ improvement (effect size) of the ACT score following treatment with choline vs. placebo. In our recent study of asthma in the elderly (2), the mean ACT score was 22.2 and the standard deviation was $2.8 \%$ $(\mathrm{n}=30)$. The calculated standardized effect size is $10 \%$ of $22.2(2.2) / 2.8=0.8$. Therefore, $\beta=0.2(1 / 0.8)$. For an $\alpha$ of 0.05 (two tailed t test) the number necessary to see a $10 \%$ change is 25 . Data were expressed as the mean \pm standard deviation and analyzed by the two tailed t test and the correlation coefficient as indicated with significance accepted at $<0.05$.

\section{Results}

Table 1 summarizes the baseline characteristics of the study subjects. Most subjects were atopic (90\%), on inhaled corticosteroids (97\%), and had well controlled asthma. As shown in Table 2, choline supplementation for 3 or 6 weeks did not affect ACT or spirometric values when compared to placebo.

Similarly, peripheral blood eosinophil counts and total serum IgE were unaffected by choline supplementation vs. placebo (Table 3$)$. In subjects with lower ACT $(\leq 20$, $16.7 \pm 3.3, \mathrm{n}=6)$, lower FEV1 \% $(<60 \%, 46.4 \pm 9.2 \%$, $n=6)$, or higher eosinophil counts $(\geq 0.6,0.88 \pm 035 \mathrm{~K} /$ 
Table 1 Subjects' characteristics at baseline

\begin{tabular}{ll}
\hline Sex (F/M) & $18 / 12$ \\
Age (years, range) & $73.7 \pm 5.9(66-84)$ \\
BMI & $25.6 \pm 4.7$ \\
Atopy & $27 / 30$ \\
Duration of asthma (years) & $34.8 \pm 21.2$ \\
Rhinitis & $23 / 30$ \\
Gastroesophageal reflux disease & $9 / 30$ \\
Inhaled steroids (dose, range) & $29 / 30(358 \pm 255,0-1000$ mcg/day) \\
Long-acting bronchodilators & $20 / 30$ \\
Leukotriene antagonists (mon- & $11 / 30$ \\
telukast) & \\
Anticholinergic agents (tiotropium) & $3 / 30$ \\
Theophylline & $1 / 30$ \\
ACT score & $22.1 \pm 3.3$ \\
FEV1 \% & $75 \pm 20.4$ \\
FEV1/FVC & $0.73 \pm 0.1$ \\
FEF25-75 \% & $71 \pm 38.2$ \\
Peripheral blood eosinophils & $0.38 \pm 0.31 \mathrm{~K} / \mu \mathrm{L}$ \\
Total serum lgE & $198 \pm 210 \mathrm{IU} / \mathrm{ml}$ \\
\hline
\end{tabular}

$\mathrm{n}=30$

Table 2 Effect of choline supplementation on ACT scores and spirometric values

\begin{tabular}{lccc}
\hline & Baseline & 3 weeks & 6 weeks \\
\hline ACT (Choline) & $22.1 \pm 3.3$ & $22.9 \pm 2.8$ & $23.4 \pm 2$ \\
ACT (Placebo) & & $23.7 \pm 1.9$ & $23.2 \pm 2.5$ \\
FEV1 \% (Choline) & $75 \pm 20.4$ & & $75.3 \pm 19.3$ \\
FEV1 \% (Placebo) & & & $76 \pm 20$ \\
FEV1/FVC (Choline) & $0.73 \pm 0.1$ & & $0.73 \pm 0.1$ \\
FEV1/FVC (Placebo) & & & $0.73 \pm 0.1$ \\
FEF25-75 \% (Choline) & $71 \pm 38.2$ & & $70 \pm 34.2$ \\
FEF25-75 \% (Placebo) & & & $71.5 \pm 34$ \\
\hline $\mathrm{n}=30$ & & & \\
$\mathrm{p}>0.86$ for all comparisons & & &
\end{tabular}

Table 3 Effect of choline supplementation on peripheral blood eosinophils counts $(\mathrm{K} / \mu \mathrm{L})$ and total serum IgE (IU/ ml)

\begin{tabular}{lll}
\hline & Baseline & 6 weeks \\
\hline Eosinophils (Choline) & $0.38 \pm 0.31$ & $0.34 \pm 0.27$ \\
Eosinophils (Placebo) & & $0.33 \pm 0.27$ \\
$\lg$ (Choline) & $198 \pm 210$ & $206 \pm 262$ \\
$\lg$ (Placebo) & & $220 \pm 285$ \\
\hline
\end{tabular}

$\mathrm{n}=30$

$p>0.84$ for all comparisons $\mu \mathrm{L}, \mathrm{n}=6)$ there was also no difference between choline and placebo (Table 4). In subjects with lower serum IgE $(\leq 151 \mathrm{IU} / \mathrm{ml}, 68.8 \pm 46 \mathrm{IU} / \mathrm{ml}, \mathrm{n}=18)$, there was a trend for a decrease of the IgE by choline supplementation vs. placebo (56.1 \pm 36.9 vs. $69 . \pm 55.4 \mathrm{IU} / \mathrm{ml}$, respectively), but this did not reach statistical significance $(\mathrm{p}=0.078)$.

We found no significant association between eosinophil counts and IgE (Table 5). Similarly, there was no association between eosinophils or IgE and ACT, age, body mass index (BMI), steroid dose, or duration of asthma (Table 5). In subjects with lower ACT scores $(16.7 \pm 3.3, \mathrm{n}=6)$, eosinophils and IgE were similar to their counterparts with controlled symptoms $(p>0.22)$. Eosinophils were similar in subjects treated with higher inhaled steroid dose ( $\geq 400 \mathrm{mcg} /$ day, $583 \pm 226, \mathrm{n}=13$ ) and subjects on lower doses $(\mathrm{p}=0.82)$. Women had lower baseline ACT scores compared to men $(21.1 \pm 3.7$ vs. $23.6 \pm 1.9$, respectively, $\mathrm{p}=0.02$ ).

Table 4 Effect of choline supplementation in different patient subgroups

\begin{tabular}{lcc}
\hline & Baseline & 6 weeks \\
\hline $\mathrm{ACT} \leq 20$ (Choline) & $16.7 \pm 3.3$ & $21.5 \pm 3$ \\
$\mathrm{ACT} \leq 20$ (Placebo) & & $22.3 \pm 2.9$ \\
$\mathrm{FEV} 1 \%<60 \%$ (Choline) & $46.4 \pm 9.2$ & $47 \pm 10.3$ \\
$\mathrm{FEV} 1 \%<60 \%$ (Placebo) & & $46.6 \pm 6.8$ \\
Eosinophils $\geq 0.6 \mathrm{~K} / \mu \mathrm{L}$ (Choline) & $0.88 \pm 0.35$ & $0.62 \pm 0.4$ \\
Eosinophils $\geq 0.6 \mathrm{~K} / \mu \mathrm{L}$ (Placebo) & & $0.62 \pm 0.5$ \\
\hline $\mathrm{n}=6$ & & \\
$\mathrm{p}>0.63$ for all comparisons & &
\end{tabular}

Table 5 Associations between different parameters at baseline

\begin{tabular}{lr}
\hline & \multicolumn{1}{l}{$\mathbf{R}$} \\
\hline Eosinophils vs. IgE & 0.180 \\
Eosinophils vs. age & 0.069 \\
Eosinophils vs. ACT & 0.071 \\
Eosinophils vs. BMI & -0.003 \\
Eosinophils vs. inhaled steroid dose & -0.034 \\
Eosinophils vs. duration of asthma & -0.308 \\
lgE vs. age & -0.243 \\
lgE vs. ACT & 0.019 \\
$\lg E$ vs. BMl & 0.154 \\
$\lg E$ vs.inhaled steroid dose & -0.145 \\
$\lg E$ vs. duration of asthma & 0.008 \\
\hline $\mathrm{n}=30$ & \\
$\mathrm{p}>0.09$ for all associations &
\end{tabular}


None of the subjects reported adverse effects during the course of the study.

\section{Discussion}

In this study, we investigated the effect of choline supplementation in elderly subjects with asthma. This group of patients has been mostly ignored in previous studies of this condition.

Choline supplementation for 6 weeks did not affect asthma symptoms or spirometric values, including in the subgroups of subjects with lower ACT scores and FEV1 values. Similarly, peripheral blood eosinophil counts and total serum IgE were unaffected by choline supplementation. These results suggest that supplementing this methyl donor has no effect on clinical and biologic parameters in elderly asthmatics. We cannot rule out that longer studies using higher doses of choline may have a different outcome. However, an open label study of Indian adults with asthma similarly showed that the same parameters were unaffected by choline chloride supplementation for 6 months [10]. Such study employed higher doses of choline than utilized in our study. In contrast, the same senior author of that study had previously reported that tricholine citrate supplementation for 16 weeks lead to an improvement in asthma symptom scores in small cohorts (10-12 subjects) of adolescent and young adults [11, 12]. One of these two studies was single blinded and the other was open label. It is unclear whether different formulations of choline may affect clinical response.

While blood eosinophil counts are similar in younger and older asthmatics, total serum IgE is significantly lower in elderly than in nonelderly asthmatic subjects [13]. In a study of adults with asthma, antigen specific serum IgE was associated with blood eosinophil counts [14]. We found no association between eosinophils and total serum IgE, or other parameters at baseline.

The results indicating that asthmatic women have lower symptom scores than men are in agreement with a recent study showing an association between female sex and poorer asthma symptom scores [15].

Although choline supplementation is considered fairly safe, and none of our study subjects experienced side effects during the study, one study found that a high dietary intake of choline was associated with an increased risk of colon adenomas in women [16].

Limitations of this study include the relatively small number of subjects, almost exclusively Caucasians and atopic with well controlled asthma. It is possible that including more subjects with uncontrolled symptoms and/or non atopic asthma could yield different results. In addition, it is also possible that choline supplementation may affect biologic markers that were not assessed in our study (e.g., cytokines, periostin).

\section{Conclusions}

In summary, in this pilot study of elderly asthmatics, choline supplementation for 6 weeks did not affect ACT scores, spirometric values, blood eosinophils or serum IgE. These results will require confirmation in subjects with uncontrolled symptoms, in other ethnic groups, and following a longer treatment period with higher dose of choline.

\section{Abbreviations}

BMI: body mass index; ACT: asthma control test.

\section{Authors' contributions}

MC participated in the study design, acquisition, interpretation and analysis of the data, in drafting and revising the manuscript. ASR participated in the acquisition of the data and in revising the manuscript. Both authors read and approved the final manuscript.

\section{Acknowledgements}

This study was supported by The Sharpe-Strumia Research Foundation of The Bryn Mawr Hospital (SSRF2014-01). This funding entity played no role in the design of the study, in the collection, analysis, and interpretation of the data, in writing the manuscript, and in the decision to submit the manuscript for publication.

\section{Competing interests}

The authors declare that they have no competing interests.

Received: 6 January 2016 Accepted: 24 February 2016

Published online: 11 March 2016

\section{References}

1. Hanania NA, King MJ, Braman SS, Saltoun C, Wise RA, Enright P, et al. Asthma in the elderly: current understanding and future research needs - a report from the National Institute on Aging (NIA) workshop. J Allergy Clin Immunol. 2011;128(Suppl):4-24.

2. Columbo M, Wong B, Panettieri RA Jr, Rohr AS. Asthma in the elderly: the role of exhaled nitric oxide measurements. Respir Med. 2013;107:785-7.

3. Columbo M, Panettieri RA Jr, Rohr AS. Asthma in the elderly: a study of the role of vitamin D. Allergy, Asthma Clin Immunol. 2014;10:48.

4. Han Y-Y, Blatter J, Brehm JM, Forno E, Litonjua AA, Celedon JC. Diet and asthma: vitamins and methyl donors. Lancet Respir Med. 2013;1:813-22.

5. Sharma S, Litonjua A. Asthma, allergy, and responses to methyl donor supplements and nutrients. J Allergy Clin Immunol. 2014;133:1246-54.

6. Blusztajn JK. Choline, a vital amine. Science. 1998;281:794-5.

7. Zeisel SH, da Costa KA. Choline: an essential nutrient for public health. Nutr Rev. 2009;67:615-23.

8. Mehta AK, Arora N, Gaur SN, Singh BP. Choline supplementation reduces oxidative stress in mouse model of allergic airway disease. Eur J Clin Invest. 2009;39:934-41.

9. Jung J, Kim SH, Lee HS, Choi GS, Jung YS, Ryu DH, et al. Serum metabolomics reveals pathways and biomarkers associated with asthma pathogenesis. Clin Exp Allergy. 2013;43:425-33.

10. Mehta AK, Singh BP, Arora N, Gaur SN. Choline attenuates immune inflammation and suppresses oxidative stress in patients with asthma. Immunobiology. 2010;215:527-34.

11. Gupta SK, Gaur SN. A placebo controlled trial of two dosages of LPC antagonist-choline in the management of bronchial asthma. Indian J Chest Dis Allied Sci. 1997;39:149-56.

12. Gaur SN, Agarwal G, Gupta SK. Use of LPC antagonist, choline, in the management of bronchial asthma. Indian J Chest Dis Allied Sci. 1997;39:107-13. 
13. Inoue H, Niimi A, Takeda T, Matsumoto H, Ito I, Matsuoka H, et al. Pathophysiological characteristics of asthma in the elderly: a comprehensive study. Ann Allergy Asthma Immunol. 2014;113:527-33.

14. Patelis A, Janson C, Borres MP, Nordvall L, Alving K, Malinovschi A. Aeroallergen and food IgE sensitization and local and systemic inflammation in asthma. Allergy. 2014;69:380-7.
15. Kannan JA, Bernstein DI, Bernstein CK, Ryan PH, Bernstein JA, Villareal MS, et al. Significant predictors of poor quality of life in older asthmatics. Ann Allergy Asthma Immunol. 2015;115:198-204.

16. Cho E, Willett WC, Colditz GA, Fuch CS, Wu K, Chan AT, et al. Dietary choline and betaine and the risk of distal colorectal adenoma in women. J Nat Cancer Inst. 2007;99:1224-31.
Submit your next manuscript to BioMed Central and we will help you at every step:

- We accept pre-submission inquiries

- Our selector tool helps you to find the most relevant journal

- We provide round the clock customer support

- Convenient online submission

- Thorough peer review

- Inclusion in PubMed and all major indexing services

- Maximum visibility for your research

Submit your manuscript at www.biomedcentral.com/submit
(OioMed Central 